RESENHA

Bookreview

\title{
MILITARY POWER: EXPLAINING VICTORY AND DEFEAT IN MODERN BATTLE ${ }^{1}$
}

\author{
Tamiris Pereira dos Santos ${ }^{2}$
}

Por que ganhadores vencem e perdedores perdem? O que define a vitória ou a derrota no campo de batalha? Seriam os avanços tecnológicos as únicas variáveis a serem consideradas no processo de modernização da Guerra? Estas são as questões norteadoras para o desenvolvimento do livro de Stephen Biddle Military Power: Explaining Victory and Defeat in Modern Battle.

Tecendo críticas acerca da ênfase conferida ao emprego da tecnologia na Guerra - considerado como Revolução nos Assuntos Militares (Revolution in Military Affairs RMA) por autores como O'Hanlon ${ }^{3}$ - Biddle constrói seus argumentos tendo como cerne explicativo que variáveis não materiais, como o emprego da força, doutrina ou tática submetidas no combate também possuem centralidade na predeterminação entre ganhadores e perdedores. Logo, a compreensão entre a interação entre variáveis materiais e não materiais se faz um elemento chave para captar as considerações de Biddle, as quais indicam que apesar da inexorabilidade de mudanças advindas de avanços tecnológicos, existem elementos de continuidade nos combates, os quais não devem ser suprimidos pela superênfase dada aos primeiros.

\footnotetext{
1 BIDDLE, Stephen M. Military Power: Explaining Victory and Defeat in Modern Battle. Princeton: Princeton University Press, 2006, 352p. ISBN: 10: 0-691-12802-2.

${ }^{2}$ Mestre em Ciências da América Latina pela Universidade de São Paulo (USP). Doutoranda em Estudos Estratégicos Internacionais pela Universidade Federal do Rio Grande do Sul (UFRGS). Email: tpsantos88@gmail.com.

3 O'HANLON, Michael E. The Science of War. New Jersey: Princeton University Press, 2009.
} 


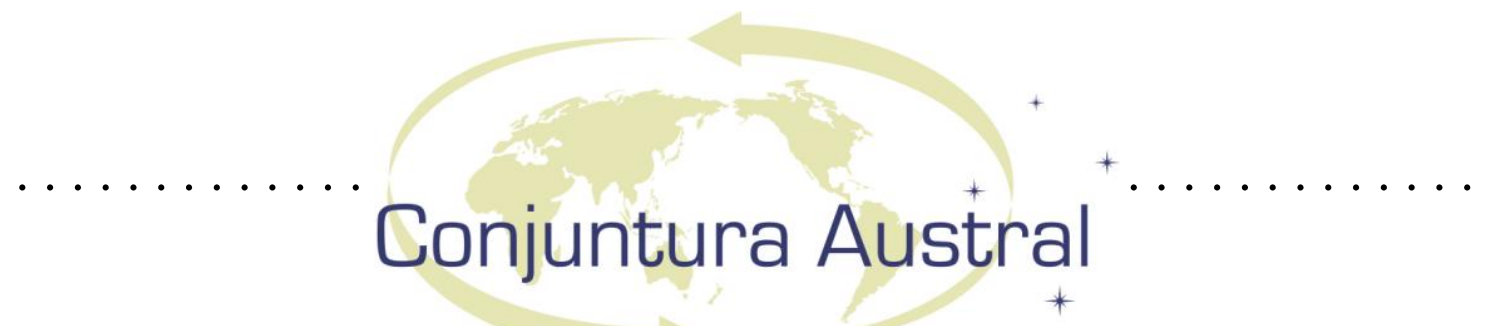

Com uma metodologia que agrega breves revisões historiográficas, considerações teóricas compreendendo visões críticas acerca da visão unitarista do Estado e do que o autor considera como uma fraca base empírica reduzida ao conceito de capacidades ${ }^{4}$, e, por fim, exploração de operações, apresentação de dados empíricos e experiências com simulações usando dados do Departamento de Defesa dos EUA (DoD - Department of Defense). Explicitações acerca do que vem a ser poder militar, a escolha por adotar as terminologias capacidade militar ofensiva e defensiva, bem como demarcações metodológicas e notas sobre os próximos capítulos compõem o capítulo introdutório do livro.

O segundo capítulo se estrutura basicamente em três partes: apresentação de concepções difundidas academicamente (preponderância numérica, tecnologia e emprego da força); confrontação destas formulações com dados empíricos, encerrando com uma análise crítica. Com este movimento, Biddle tenta demonstrar a insuficiência explicativa no âmbito da teoria em seus esforços para delimitar o conceito de capacidade, trazendo à baila a demanda por uma nova variável explicativa - a saber, o emprego da força - a fim de formalizar uma compreensão acerca de capacidade que não contemple apenas preponderância e tecnologia.

Neste sentido o terceiro capítulo propõe um delinear do emprego da força no âmbito do que o autor intitula como Sistema Moderno ${ }^{5}$ a partir de quatro etapas: 1) revisão das mudanças tecnológicas ocorridas ao final do século XIX, as quais tornaram o poder de fogo como questão central para operações e táticas a posteriori; 2) breve estudo das alternativas provenientes do Ocidente para a questão do poder de fogo ao

\footnotetext{
${ }^{4}$ Crítica direcionada à formulação teórica de Waltz (1979), o realismo estrutural, apresentado em Theory of International Politics.

${ }^{5}$ Conforme considerações do autor ao longo do capítulo, o Sistema Moderno seria um arranjo baseado na organização tática em batalha, contendo elementos para táticas ofensivas e defensivas; os elementos principais das táticas ofensivas seriam: abrigo, encobrimento, dispersão, manobras independentes de unidades pequenas, supressão, integração de forças combinadas e limitação de alvos, a fim de destruir posições defensivas inimigas mesmo ante o fogo pesado; os elementos nas táticas defensivas seriam: profundidade, reservas e contra-ataque. Neste sentido, a efetividade do sistema habita muito na habilidade das tropas em aplicar tais táticas, questão discutida pelo autor ao fim do capítulo mencionado, quando o autor pondera que fatores de origem política, cultural e organizacional tiram os Estados da rota de adoção de doutrinas militares baseadas no Sistema moderno, sendo que o peso destes fatores varia de Estado para Estado (BIDDLE, 2006).
} 


\section{Conjuntura Austral}

longo da Primeira Guerra Mundial, apresentando como estas orquestraram uma espécie de padrão, intitulado pelo autor como o sistema moderno de emprego da força; 3 ) demonstração do funcionamento do Sistema Moderno e como este possibilitou a resistência das Forças Armadas ao crescente potencial do poder de fogo; 4) balanço das dificuldades organizacionais e políticas em se implementar o Sistema Moderno - as variações no emprego da força e as dificuldades organizacionais e políticas dos Estados.

O quarto capítulo, também disposto em quatro partes, se destina a demonstrar de forma comparativa as mudanças tecnológicas e em que grau estas afetaram a aplicação do Sistema Moderno, apresentando tendências para o futuro e considerações da aplicação teórica proposta. Rememorando os casos da Guerra do Afeganistão e em Kosovo, o autor explicita que o emprego da tecnologia para o avanço do poder de fogo e da letalidade aumentaram a significância do Sistema Moderno e suas estratégias, revelando que os elementos que compõem as táticas ofensivas e defensivas deste modelo não foram mitigados pelos avanços tecnológicos através de demonstrações gráficas, negando a abordagem da preponderância numérica em combate e comparando efeitos em no Sistema Moderno e "não moderno".

Após dois capítulos com esforços de demarcação teórica em meio a concepções às quais Biddle se posiciona criticamente, os três capítulos subsequentes (quinto, sexto e sétimo) lidam diretamente com análises das Operações Michael (2 $2^{\mathrm{a}}$ Batalha do Somme, França - 21/03 a 9/04/1918), Goodwood (Região da Normândia - 18 a 20/07/1944) e Desert Storm (Golfo Pérsico - 17/01 a 28/02/1991), estruturando-se em justificativa de análise para as Operações mencionadas, apresentação de variáveis independentes, táticas ofensivas e defensivas, e um balanço geral contemplando pontos de convergência e divergência com a proposta teórica do Sistema Moderno, além de implicações.

Após um delinear com estudos de caso, Biddle inclui de forma mais expressiva, ao longo do oitavo capítulo, as componentes empíricas para analisar o Sistema Moderno ou "Nova Teoria", apresentando dados da Michigan's Correlates of War (COW), de um banco de dados das Forças Armadas dos EUA intitulado $\mathrm{CDB}^{6}{ }^{6}$, bem como uma compilação de dados acerca de sofisticação tecnológica em dezesseis situações de pós-

\footnotetext{
${ }^{6}$ Referente as 660 batalhas que tiveram lugar entre 1600 e 1982 (BIDDLE, 2006).
} 


\section{Conjuntura Austral}

guerra no período de 1956 a 1992, denominada pelo autor de MILTECH. A manobra apresentada neste capítulo, além de aferir um conteúdo estatístico, foi a de comparar a Nova Teoria com as formulações ortodoxas, resgatando as concepções difundidas academicamente $^{7}$ para inseri-las em diversas hipóteses. Estas, por sua vez, compreendem como parâmetros a análise da preponderância numérica em relação de forças terrestres (FFR - Force-to-Force Ratio), força terrestre e força espacial (FSR Force-to-Space Ratio), tecnologia de forma sistêmica e de forma dual, no âmbito das baixas militares, ganho territorial e duração. Finalizado o "teste" empírico a fim de validar a Nova Teoria, Biddle procede às experimentações com a simulação em computadores ao nono e penúltimo capítulo, esclarecendo que os modelos não pressupõem teorias de combate, mas ferramentas para análise teórica no âmbito previamente demarcado pelo autor.

No último capítulo, dedicado à conclusão, Biddle retoma os questionamentos previamente tratados, relacionados à proposição de capacidade, emprego da força e a limitação da componente material como determinante para o lado vitorioso, estruturando a seguir o capítulo em partes: implicações da Nova Teoria para a academia, contemplando críticas para as visões difundidas negadas à vista de sua formulação teórica, bem como recomendações, e implicações para a política.

Revisando considerações acerca da Nova Teoria, o autor demonstra como esta formulação privilegia a visão do conceito de capacidade de forma abrangente e multidimensional, a fim de contemplar de forma menos estreita a referida questão no âmbito militar - comparando a forma como as Relações Internacionais lidam com a temática. Quanto às considerações da Nova Teoria para o âmbito da política, o autor desenvolve seis pontos que considera principais enquanto concernentes ao futuro da guerra: as prioridades do orçamento de defesa, estrutura da força, desenvolvimento e aquisição de armamentos, avaliação da campanha conjunta e a doutrina militar. Apesar de considerar todos os referidos pontos, as principais críticas do autor ao longo da apresentação da Nova Teoria repousaram em prover uma visão alternativa para a supervalorização do âmbito material e tecnológico da guerra, superdimensionando estas

\footnotetext{
${ }^{7}$ Objeto de análise sucinta ao segundo capítulo do livro.
} 


\section{Conjuntura Austral}

componentes no âmbito da RMA e negligenciando o desdobramento da capacidade como questão não material, através do componente tático por exemplo.

Portanto, o trabalho de Biddle visa contribuir para uma ampliação dos horizontes de estudos da guerra para além da estratégia do unitarismo, presente em algumas formulações teóricas específicas nas RI, e para além do exacerbado entusiasmo demonstrado por estudiosos que advogam a tecnologia como condição sine qua non para a obtenção de vitórias nas batalhas face ao fenômeno do RMA, fornecendo parâmetros de contraponto interessantes para o desenvolvimento de estudos que tenham a multidimensionalidade como pressuposto.

Resenha recebida dia 10 de março de 2013. Aprovado em 20 de agosto de 2013. 